\title{
Students' Perceptions of Class Activities: An Investigation into the Role of Gender and Grade Level
}

\section{Esmaeil Aryan}

MA in TEFL, Yasuj Branch, Islamic Azad University, Yasuj, Iran

Mohsen Shahrokhi

Corresponding Author, Assistant Professor, Shahreza Branch, Islamic Azad University, Shahreza, Isfahan, Iran Email: shahrokhi1651@yahoo.com

\author{
Doi:10.5901/mjss.2015.v6n4s1p19
}

\section{Abstract}

This study examined whether differences existed in perceptions of class activities for students of different proficiency level and gender. Pre-intermediate and intermediate students of English on one hand, and upper-intermediate and advanced students of English on the other. To this end, the frequency of students perceived opportunities for interest, challenge, choice, and enjoyment in their classrooms was assessed using the affective instrument which was originally constructed by Gentry and Gable (2001). Results revealed that significant main effects existed for proficiency level of the students and their gender, with no significant interaction of the two variables under investigation. In general, upper-intermediate and advanced learners of English found their classroom activities less interesting and enjoyable and with fewer opportunities for choice, than did preintermediate and intermediate students. Moreover, female learners showed that their class activities were more interesting and enjoyable.

Keywords: students' perceptions, class activity, motivation, gender, proficiency level

\section{Introduction}

It has been depicted by research on second language learners 'motivation and motivational classroom activities that many external factors such as pees, parents, teachers, and friends have effect on EFL learners ' motivation (Brophy, 2010; Sugita \& Takeuchi, 2010; Bernaus \& Gardner, 2008; Nakata, 2006; Dornyei, 1994). Both students' motivation and language proficiency are greatly affected by students' classroom experiences (Nikolov, 1999). Teachers' classroom practices and strategies play the most effective role in motivating EFL learners.

As students move toward higher proficiency levels, some negative changes might be noticed in their achievement, attitude and degree of motivation. These changes are mainly influenced by environments, peer groups and teachers. A great deal of research has investigated the differences between boys and girls on miscellaneous variables including achievement, attitude, and self-concept. Dornyei (1998) conducted a study on 50 learners learning English or German as foreign languages and found that the most demotivating factorswere teaching-related inappropriate practices and strategies.

Gorham and Christopher (1992) conducted a large-scale quantitative study to investigate motivators and demotivate of students at West Virginia University in the USA and concluded that teachers' negative classroom practices and behaviors are the primary causes of students' demotivation teachers' negative classroom practices and behaviors. there has been a great deal of research done in the sphere of student motivation, specifically concerning changes in motivation, as students' progress from elementary levels of proficiency to upper intermediate levels and finally advanced levels of language use.

Gender differences among children and adolescents have been frequently studied, with girls often reported as typically more motivated than boys (e.g., Burke, 1989). There is a wide array of literature that describes the differences between boys and girls on a variety of variables including achievement, attitude, locus of control, and self-concept. Burke (1989) found that there were general differences in academic performances between boys and girls but suggested more research is needed to understand the reasons for these differences. Some researchers have suggested achievement differences are due to differences in self-esteem (Orenstein, 1994), whereas others believe locus of control is a primary reason (Boss \& Taylor, 1989). 
The ultimate goal of any language related educational program is to enhance students' degree of achievement through-out the course of instruction. The exploration of students' conceptions of different classroom activities provide teachers with useful and to the point feedback which helps teachers improve the quality within their classrooms. The findings of this type of studies can help language teachers to better the quality of learning within their classroom by accentuating the importance of exploring students' view of what is happening in the class. This way, teachers can make informed decision on how to go about their teaching and how to improve motivation within learners.

As mentioned above, many studies have been done on the impacts of different variables on adolescent and children's achievement. All of these studies were done in the context of education, having no implications for language learners. To fill this gap, this study tries to investigate what language learners' perceptions of classroom activities are and whether there is any interaction between students' gender and proficiency level. That being said, this study tries to investigate if learners' gender and proficiency level affect their perceptions of classroom activities.

\section{This Study}

This study aimed at investigating the perceptions of Iranian language learners of different classroom activities in Yasuj city in Iran. It, therefore, sought to find out what learners think of class activities and whether these activities, in their view, could lead to the promotion of their motivation and achievement. Moreover, the current research aimed to investigate if there is any interaction between the differences in the attitudes and perceptions of boys and girls and their levels of proficiency. Consequently, in an attempt to achieve these aims the following research questions were formulated.

- Is there any significant difference among students' perceptions of their class activities as far as proficiency level is concerned?

- Is there any significant difference among students' attitudes toward classroom activities as far as gender is concerned?

- Is there any significant interaction between gender and grade level in terms of students perceptions of their class activities?

The following research hypotheses were stated based on the questions mentioned above.

- There is no significant difference among students' perceptions of their class activities as far as proficiency level is concerned.

- There is no significant difference among students' attitudes toward classroom activities as far as gender is concerned.

- There is no significant interaction between gender and grade level in terms of students perceptions of their class activities.

\section{Method}

\subsection{Participants}

The researcher of this study was used 70 language learners of English from different levels. Their language proficiency ranged from pre-intermediate to advance. Their age ranged from 18 to 25. They were all adult learners of English, learning English in different institutes located in the city of Yasuj, Iran.

\subsection{Instruments}

\subsubsection{Oxford Placement Test (OPT)}

An Oxford Placement Test (OPT) was used to determine students' level in terms of proficiency. Students were then classified as pre-intermediate, intermediate, upper intermediate and advanced.

\subsubsection{The Survey Instrument}

A questionnaire called My Class Activities (Gentry \& Gable, 2001), was administered in two versions; that is, Persian for low proficient group and English for high proficient group to a sample of students in different Grades (levels) studying English in the city of Yasuj. It contained 31 statements assessing four dimensions (interest, challenge, choice, and enjoyment), using a 5-point Likert-type response format (never, seldom, sometimes, often, and always). These items 
were submitted to 16 content experts who were asked to assign them to respective categories and then indicate how confident they were with these assignments. On the basis of this judgmental feedback, items were selected for a pilot instrument (Gentry, Maxfield, \& Gable, 1998). Validity evidence for construct interpretation was investigated through confirmatory factor analysis. A goodness of fit index of .95 was obtained which showed questionnaire was valid. Cronbach Alpha was run to see how much internal consistency the questionnaire has. The results showed that the Cronbach Alpha was .78 which is fairly a good index of reliability.

\subsection{Data Analysis}

After collecting the required data, a number of statistical tests were performed to investigate the research hypotheses. SPSS (Statistical Package for Social Sciences) Version 22 was used to perform all the statistical analyses in this study. To examine the three research hypotheses, descriptive statistics are reported separately in each section and a two-way analyses of variance (MANOVA of Grade Level \& Gender for the set of variables: interest, challenge, choice, and enjoyment) was conducted on each dependent variable to see whether there were any statistically significant differences across the groups. The minimum alpha for confirmation of the research hypotheses was .05 .

\section{Results}

In this part of the article, the results of the study will be provided. A questionnaire was administered to 70 Iranian EFL learners to collect the data needed to find answers to the research questions of this study. Thus for ease of the interpretation, students were divided into high and low proficient groups.

It aimed to measure four constructs (namely, choice, enjoyment, interest, and challenge) each of which had been designed to shed some light and measure different aspects of activities used in language classrooms, in the context of Iran. The researcher of the study decided to combine the scales (always+ often) together. Moreover, he combined the scales (never+ seldom) with one another. In so doing, he aimed to facilitate the process of data interpretation.

\subsection{Results of pre-inter mediate and intermediate students (Low proficient group)}

35 pre/intermediate language learners voluntarily took part in the study by filling out the questionnaire. Below, students' views on each construct of the questionnaire will be discussed separately

\subsubsection{Construct 1: Interest}

This construct consisted of 8 Likert-type items whose scale ranged from "always" to "never". The majority of pre/intermediate students (68.5 percent) maintained that what they learn in class is interesting to them. The highest means in this table belonged to item 6 and 1 . The lowest means in this construct belonged to items 3 and 5 respectively (item 3: $M=2.22$, item $5: M=2.71$ ). Then it can be concluded that the majority of students seldom come up with new and interesting ideas while doing language related activities.

Table 1. Construct 1, Pre-intermediate and Intermediate Students

\begin{tabular}{|c|c|c|c|c|c|c|c|}
\hline \multirow[t]{2}{*}{ Construct 1= Interest } & \multicolumn{2}{|c|}{ Always + Often } & \multicolumn{2}{|c|}{ Sometimes } & \multicolumn{2}{|c|}{ Seldom + Never } & \multirow[t]{2}{*}{ Mean } \\
\hline & $\mathrm{F}$ & $P$ & $\mathrm{~F}$ & $\mathrm{P}$ & $\mathrm{F}$ & $\mathrm{P}$ & \\
\hline 1. What I do in my class fits my interests. & 23 & 65.7 & 7 & 20 & 5 & 14.3 & 3.51 \\
\hline 2. I have an opportunity to work on things in my class that interest me. & 14 & 40 & 15 & 42.8 & 6 & 17.2 & 3.28 \\
\hline 3. What I do in my class gives me interesting and new ideas. & 7 & 20 & 9 & 25.7 & 19 & 54.2 & 2.22 \\
\hline 4. I study interesting topics in my class. & 4 & 11.4 & 17 & 48.5 & 14 & 40 & 3.45 \\
\hline 5. The teacher involves me in interesting learning activities. & 6 & 17.2 & 19 & 54.2 & 10 & 28.6 & 2.71 \\
\hline 6. What I learn in my class is interesting to me. & 24 & 68.5 & 8 & 22.8 & 3 & 8.5 & 3.6 \\
\hline 7. What I do in my class is interesting. & 13 & 37.1 & 17 & 48.5 & 5 & 14.3 & 3.25 \\
\hline 8. My class has helped me explore my interests. & 9 & 25.7 & 18 & 51.4 & 8 & 22.8 & 2.97 \\
\hline
\end{tabular}




\subsubsection{Construct 2: Challenge}

This construct consisted of 9 likert-type items. The highest means in this construct belonged to item 2 and item 1 (item 2 : $M=3.48$, item 1: $M=3.31$ ). Since the means of these two items are above 3 (equivalent to "sometimes" in the scale) it can be inferred that majority of students sometimes have to deal challenging language activities which require intensive mental processing. On the contrary, the lowest means in this construct belonged to item 6 and item 9 , respectively (item 6: $M=2.08$, Item 9: $M=2.45$ ). This indicates that although language classes might sometimes be replete with activities which require intensive mental processing, they seldom are considered as difficult or demanding because of the students' intrinsic motivation to learn a given language.

Table 2. Construct 2, Pre-intermediate and Intermediate Students

\begin{tabular}{lccccccc}
\hline \multirow{2}{*}{ Construct 2=challenge } & Always & Often & \multicolumn{3}{c}{ Sometimes } & \multicolumn{3}{c}{ Seldom + Never } & Mean \\
& $\mathrm{F}$ & $\mathrm{P}$ & $\mathrm{F}$ & $\mathrm{P}$ & $\mathrm{F}$ & $\mathrm{P}$ & \\
\hline 1. The activities I do in my class are challenging & 18 & 51.4 & 10 & 28.6 & 7 & 20 & 3.31 \\
\hline 2. I have to think to solve problems in my class. & 20 & 57.1 & 11 & 31.4 & 4 & 11.4 & 3.48 \\
\hline 3. I use challenging materials and books in my class. & 17 & 48.5 & 12 & 34.2 & 6 & 17.2 & 3.25 \\
\hline 4. I challenge myself by trying new things. & 11 & 31.4 & 16 & 45.7 & 8 & 22.8 & 2.97 \\
\hline 5. My work can make a difference. & 4 & 11.4 & 7 & 20 & 24 & 68.5 & 2.68 \\
\hline 6. I find the works in this class demanding. & 4 & 11.4 & 12 & 34.2 & 19 & 54.4 & 2.08 \\
\hline 7. I am challenged to do my best in class. & 7 & 20 & 14 & 40 & 14 & 40 & 2.51 \\
\hline 8. What we do in class fits my abilities. & 12 & 34.2 & 17 & 48.5 & 6 & 17.2 & 3.11 \\
\hline 9. This class is difficult. & 5 & 14.3 & 16 & 45.7 & 14 & 40 & 2.45 \\
\hline
\end{tabular}

\subsubsection{Construct 3: choice}

This construct consisted of 7 items. They do not have any choice in language classrooms while performing a given task. This indicates that language classrooms in the context of our country, regardless of the proficiency level of the students is teacher-centered, in which the teacher is the only active authority who should make decision on behalf of the students about the curriculum, syllabus, teaching materials and the like. In this construct, as Table 3 indicates, the lowest mean belonged to item $7(M=1.48)$ and the highest mean $(M=2.22)$, in this construct belonged to item 4. This shows that students were seldom free to choose their own project or activities to take part in.

Table 3. Construct 3, Pre-intermediate and Intermediate Students

\begin{tabular}{lccccccc}
\hline \multirow{2}{*}{ Construct3=choice } & \multicolumn{3}{c}{ Always + Often } & \multicolumn{3}{c}{ Sometimes Seldom + Never Mean } \\
& F & $P$ & $F$ & $P$ & $F$ & $P$ \\
\hline 1. I can choose to work in a group. & 2 & 5.7 & 10 & 28.6 & 23 & 65.7 & 2.17 \\
\hline 2. I can choose to work alone. & 3 & 8.5 & 7 & 20 & 25 & 71.4 & 1.94 \\
\hline 3. When we work together, I can choose my partners. & 3 & 8.5 & 8 & 22.8 & 24 & 68.5 & 2.05 \\
\hline 4. I can choose my own projects. & 7 & 20 & 6 & 17.2 & 22 & 62.8 & 2.22 \\
\hline 5. When there are many jobs, I can choose the ones that suit me. & 0 & 0 & 15 & 42.8 & 10 & 28.6 & 1.71 \\
\hline 6. I can choose materials to work within the class. & 3 & 8.5 & 11 & 31.4 & 15 & 42.8 & 2.11 \\
\hline 7. I can choose an audience for my product. & 0 & 0 & 7 & 20 & 28 & 80 & 1.48 \\
\hline
\end{tabular}

\subsubsection{Construct 4: Enjoyment}

As Table 4 shows, all means of the items of this construct are above 3 which manifests that the majority of the students were enjoying their language classes despite all the limitations and deficiencies of teaching programs in Iran. 
Table 4: Construct 4: Pre-intermediate and Intermediate Students

\begin{tabular}{lccccccc}
\hline \multirow{2}{*}{ Construct 4=enjoyment } & Always + Often & \multicolumn{2}{c}{ Sometimes } & \multicolumn{2}{c}{ Seldom + Never } & Mean \\
& F & P & F & P & F & P & \\
\hline 1. I look forward to my class. & 17 & 77.1 & 3 & 8.5 & 5 & 14.3 & 3.6 \\
\hline 2. I have fun in my class. & 18 & 80 & 2 & 5.7 & 5 & 14.3 & 3.74 \\
\hline 3. The teacher makes learning fun. & 26 & 74.2 & 4 & 11.4 & 5 & 14.3 & 3.68 \\
\hline 4. I like what I do in my class. & 7 & 20 & 25 & 71.4 & 3 & 8.5 & 3.17 \\
\hline 5. I like working in a class. & 8 & 22.8 & 23 & 65.7 & 4 & 11.4 & 3.14 \\
\hline 6. The activities I do in my class are enjoyable. & 20 & 57.1 & 9 & 25.7 & 6 & 17.2 & 3.54 \\
\hline 7. I like the projects I work on in my class. & 8 & 22.8 & 22 & 62.8 & 5 & 14.3 & 3.14 \\
\hline
\end{tabular}

\subsection{Results of Upper-intermediate and advanced students (high proficient group)}

35 upper-intermediate and advanced language learners voluntarily took part in the study by filling out the questionnaire. Below, students' views on each construct of the questionnaire will be discussed separately.

\subsubsection{Construct 1: Interest}

As Table 5 shows the degree of interest toward English classes and activities has reduced within upper-intermediate and advanced learners of English compared to that of the pre-intermediate and intermediate ones. The highest mean in this construct belongs to item $1(M=3.08)$. On the contrary, the lowest mean belongs to item $3(M=2.11)$. This indicates that, first of all, sometimes the classroom activities fit students' interests and preferences and secondly nearly most of these activities do not contribute to any creative and new ideas within students.

Table 5. Construct 1, Upper-intermediate and Advanced Students

\begin{tabular}{|c|c|c|c|c|c|c|c|}
\hline \multirow{2}{*}{ Construct $1=$ Interest } & \multicolumn{2}{|c|}{ Always + Often } & \multicolumn{2}{|c|}{ Sometimes } & \multicolumn{2}{|c|}{ Seldom + Never } & \multirow[t]{2}{*}{ Mean } \\
\hline & $\mathrm{F}$ & $P$ & $\mathrm{~F}$ & $P$ & $\mathrm{~F}$ & $P$ & \\
\hline 1. What I do in my class fits my interests. & 14 & 40 & 10 & 28.6 & 11 & 31.4 & 3.08 \\
\hline 2. I have an opportunity to work on things in my class that interest me. & 10 & 28.6 & 12 & 34.2 & 13 & 37.1 & 2.74 \\
\hline 3. What I do in my class gives me interesting and new ideas. & 3 & 8.5 & 7 & 20 & 25 & 71.4 & 2.11 \\
\hline 4. I study interesting topics in my class. & 5 & 14.3 & 12 & 34.2 & 18 & 51.4 & 2.65 \\
\hline 5. The teacher involves me in interesting learning activities. & 6 & 17.2 & 10 & 28.6 & 19 & 54.4 & 2.65 \\
\hline 6. What I learn in my class is interesting to me. & 3 & 8.5 & 14 & 40 & 18 & 51.4 & 2.17 \\
\hline 7. What I do in my class is interesting. & 5 & 14.3 & 13 & 37.1 & 17 & 48.5 & 2.54 \\
\hline 8. My class has helped me explore my interests. & 7 & 20 & 14 & 40 & 14 & 40 & 2.71 \\
\hline
\end{tabular}

\subsubsection{Construct 2: Challenge}

The highest mean among the items of this construct belongs to item $9(M=3.51)$. This is in contrast with the findings obtained from Pre-intermediate and intermediate students, most of whom claimed that their class was not difficult and demanding at all. As Table 6 indicates, nearly most of the students claimed that language classrooms are demanding and difficult to deal with $(M=3.51)$. On the contrary, the lowest mean, in this construct, belongs to item 8 .

Table 6. Construct 2, Upper-intermediate and Advanced Students

\begin{tabular}{lccccccc}
\hline \multirow{2}{*}{ Construct 2=challenge } & Always + Often & \multicolumn{3}{c}{ Sometimes } & \multicolumn{3}{c}{ Seldom + Never } \\
& Mean \\
& $\mathrm{F}$ & $\mathrm{P}$ & $\mathrm{F}$ & $\mathrm{P}$ & $\mathrm{F}$ & $\mathrm{P}$ & \\
\hline 1. The activities I do in my class are challenging & 17 & 48.5 & 14 & 40 & 4 & 11.4 & 3.48 \\
\hline 2. I have to think to solve problems in my class. & 18 & 51.4 & 12 & 34.2 & 5 & 14.3 & 3.4 \\
\hline 3. I use challenging materials and books in my class. & 16 & 45.7 & 12 & 34.2 & 7 & 20 & 3.28 \\
\hline 4. I challenge myself by trying new things. & 14 & 40 & 17 & 48.5 & 4 & 11.4 & 3.42 \\
\hline 5. My work can make a difference. & 13 & 37.1 & 10 & 28.6 & 12 & 34.2 & 2.91 \\
\hline 6. I find the works in this class demanding. & 14 & 40 & 18 & 51.4 & 3 & 8.5 & 3.4 \\
\hline 7. I am challenged to do my best in class. & 18 & 51.4 & 12 & 34.2 & 5 & 14.3 & 3.48 \\
\hline 8. What we do in class fits my abilities. & 6 & 17.2 & 10 & 28.6 & 19 & 54.4 & 2.17 \\
\hline 9. This class is difficult. & 20 & 57.1 & 8 & 22.8 & 7 & 20 & 3.51 \\
\hline
\end{tabular}




\subsubsection{Construct 3: choice}

As Table 7 indicates, upper-intermediate and advanced students rarely have a choice in language classrooms. Their lack of choice in language classrooms is very similar to that of pre-intermediate and intermediate students (Total mean of pre/intermediate students $=13.66$, Total mean of upper-intermediate and advanced students=14.29). This might be mainly due to the nature of language classrooms in Iran which are mostly teacher-centered and governed based on the principles of Audio-lingual method.

Table 7. Construct 3, Upper-intermediate and Advanced Students

\begin{tabular}{|c|c|c|c|c|c|c|c|}
\hline \multirow{2}{*}{ Construct 3=choice } & \multicolumn{2}{|c|}{ Always + Often } & \multicolumn{2}{|c|}{ Sometimes } & \multicolumn{2}{|c|}{ Seldom + Never } & \multirow[t]{2}{*}{ Mean } \\
\hline & $\mathrm{F}$ & $\mathrm{P}$ & $\mathrm{F}$ & $\mathrm{P}$ & $\mathrm{F}$ & $P$ & \\
\hline 1. I can choose to work in a group. & 32 & 8.5 & 12 & 34.2 & 20 & 57.1 & 1.91 \\
\hline 2. I can choose to work alone. & 5 & 14.3 & 13 & 37.1 & 17 & 48.5 & 2.34 \\
\hline 3. When we work together, I can choose my partners. & 7 & 20 & 3 & 8.5 & 25 & 71.4 & 2.17 \\
\hline 4. I can choose my own projects. & 5 & 14.3 & 7 & 20 & 23 & 65.8 & 2.02 \\
\hline 5. When there are many jobs, I can choose the ones that suit me. & 3 & 8.5 & 6 & 17.2 & 26 & 74.2 & 1.91 \\
\hline 6. I can choose materials to work within the class. & 6 & 17.2 & 5 & 14.3 & 24 & 68.5 & 2.17 \\
\hline 7. I can choose an audience for my product. & 3 & 8.5 & 4 & 11.4 & 28 & 80 & 1.77 \\
\hline
\end{tabular}

\subsubsection{Construct 4: Enjoyment}

As learners have no choice to and their needs are not taken into account by teachers during instruction, it should be said that the extent to which students enjoyed their language classes and the activities performed in it was much lower than that of pre-intermediate and advanced students (Total mean of pre/intermediate students $=24.01$, Total mean of upperintermediate and advance students= 13.69). That is why both their interest in learning English and the degree of their enjoyment in language classrooms have drastically declined over time.

Table 8. Construct 4, Upper-intermediate and Advanced Students

\begin{tabular}{|c|c|c|c|c|c|c|c|}
\hline \multirow{2}{*}{ Construct 4=enjoyment } & \multicolumn{2}{|c|}{ Always + Often } & \multicolumn{2}{|c|}{ Sometimes } & \multicolumn{2}{|c|}{ Seldom + Never } & \multirow[t]{2}{*}{ Mean } \\
\hline & $\mathrm{F}$ & $\mathrm{P}$ & $\mathrm{F}$ & $P$ & $\mathrm{~F}$ & $\mathrm{P}$ & \\
\hline 1. I look forward to my class. & 6 & 17.2 & 3 & 8.5 & 26 & 74.2 & 2.22 \\
\hline 2. I have fun in my class. & 4 & 11.4 & 2 & 5.7 & 29 & 82.8 & 1.77 \\
\hline 3. The teacher makes learning fun. & 2 & 5.7 & 5 & 14.3 & 28 & 80 & 1.8 \\
\hline 4. I like what I do in my class. & 3 & 8.5 & 5 & 14.3 & 27 & 77.1 & 1.97 \\
\hline 5. I like working in a class. & 2 & 5.7 & 6 & 17.2 & 27 & 77.1 & 1.91 \\
\hline 6. The activities I do in my class are enjoyable. & 3 & 8.5 & 4 & 11.4 & 28 & 80 & 1.91 \\
\hline 7. I like the projects I work on in my class. & 3 & 8.5 & 7 & 20 & 25 & 71.4 & 2.11 \\
\hline
\end{tabular}

\subsection{Gender differences in the four constructs}

As it can be seen in Table 9, in terms of all the constructs of the questionnaire, the total means obtained from girls was higher than boys.

Table 9. Gender Differences in the Four Constructs

\begin{tabular}{|c|c|c|c|c|c|c|c|}
\hline Grade levels & $\begin{array}{c}\text { Interest Girls } \\
\text { Boys }\end{array}$ & \multicolumn{2}{|c|}{$\begin{array}{c}\text { Challenge Girls } \\
\text { Boys }\end{array}$} & \multicolumn{2}{|c|}{$\begin{array}{c}\text { Choice Girls } \\
\text { Boys }\end{array}$} & \multicolumn{2}{|c|}{$\begin{array}{c}\text { Enjoyment Girls } \\
\text { Boys }\end{array}$} \\
\hline 1. pre-intermediate \& intermediate students & $\begin{array}{l}3.20 \\
3.03\end{array}$ & 3.00 & 2.74 & 2.05 & 1.88 & 3.63 & 3.22 \\
\hline 2. upper-intermediate and advanced students & $\begin{array}{l}2.73 \\
2.45\end{array}$ & 3.36 & 3.08 & 2.15 & 1.91 & 2.06 & 1.84 \\
\hline
\end{tabular}




\subsection{Inferential statistics}

As shown in Table 10, there were significant differences for the two-way ANOVA of the main effects of grade level and gender with no significant interaction of grade level and gender. Thus, it can be concluded that the first and second null hypothesis would be rejected, but the third null hypothesis would be confirmed.

Table 10. Results of two-way ANOVA

\begin{tabular}{lccccc}
\hline Source & df & Mean square & $F$ & Sig & Partial Eta Squared \\
\hline Correct model & 35 & 973.605 & 10.571 & .000 & .424 \\
Intercepts & 2 & 2910152 & 31596 & .000 & .982 \\
Gender & 1 & 858.492 & 4.3715 & .01 & .007 \\
Grade level & 2 & 153.452 & 20.12323 & .001 & .322 \\
Grade level \& gender & 3 & 403.692 & 1.666 & .14 & .043 \\
\hline
\end{tabular}

\section{Discussion and Conclusion}

As mentioned earlier, students' perceptions of their class activities with an investigation into the role of gender and grade level were investigated. Results showed that students' degree of interest was high, because they maintained learning anything in class was interesting to them and they were extremely motivated and enthusiastic to fill out the questionnaire and to learn English. Regarding challenge, it could be concluded that the majority of students have to cope with challenging language practices which require intensive mental processing and class activities seldom are taken into account as difficult and demanding because students were intrinsically motivated to learn a given language. In addition, students were not considered as active agents in class, because they did not have any choice in classrooms while performing a given task. It is suggested that this lack of choice is related to the teacher-centeredness of classes in our country and teacher makes decisions instead of students about everything related to classroom; that is, designing a course, teaching, and curriculum.

Findings indicated that all means of the items are above three, showing that language classes were enjoyable for most of the students as there were some limitations and deficiencies for teaching programs in Iran. Results of high proficient levels in terms of constructs; that is, interest, challenge, choice, and enjoyment indicated that their degree of interest and enjoyment was much lower than that of low proficient levels according to their means. In terms of challenge they maintained that their class was not difficult and demanding at all, which is against low proficient ones. Both high and low proficient groups are very similar as to lack of choice in their classes, because language classes are not learnercentered and governed based on principles of Audio-lingual method.

Results revealed that there was a significant difference between students' perceptions and attitudes toward their classroom activities as far as gender and proficiency level are concerned; but there was no significant interaction between them. Bruke (1989) found that there were general differences in academic performances among boys and girls on a variety of variables including achievement, attitude, and locus of control, and self-concept, which is in line with the findings of this study, since girls had higher means in all of the constructs. Cray and Currie (1996) maintained that teachers do not have to act on behalf of their learners, but with their learners which is parallel to the discoveries of this search, as classes were teacher-centered and they did not take students' needs and preferences into account. Therefore, there should be a combination of teachers and learners' views to make the quality of learning better.

It worth mentioning that student views and perceptions are important areas to consider when designing effective educational experiences. In language institute reform efforts, emphasis is often placed on achievement measures, whereas student attitude also plays a large role in the success of language academies. We have provided student insights concerning their views of their class activities regarding affective areas tied to learning. Findings of grade level and gender differences in these areas add valuable data to consider when developing student programs. EFL/ESL teachers and educators should take note of these findings and investigate whether increasing opportunities for and emphasis on interest, choice, and enjoyment would increase student motivation and satisfaction with their class activities. Incorporating more interest, choice, and enjoyment in curricular and instructional planning might serve to increase satisfaction with school, motivation, and, in turn, achievement. Additional attention might be paid to the overall and consistently lower scores of boys than girls in the area of enjoyment and in some instances interest across proficiency levels. Therefore, both pre/intermediate and advanced EFL teachers might consider means to engage their male students in more enjoyable learning experiences. 
Like all other studies, the present research also had some limitations. According to Dornyei (2007) a survey, which includes the administration of a questionnaire to a sample of given population should be given to a minimum of 100 participants. Since the questionnaire used in this study was given to only 70 participants, the data yielded cannot be generalized because of the small sample sizes. There are some reasons for this small sample size as follows: In the context of Yasuj city in Iran, students do not normally consider the act of filling out a questionnaire seriously. Another problem had to do with the fact that most institutes did not allow the researcher to ask students to fill out the questionnaire in language classrooms. Therefore, students had to embark on answering the questionnaire after the class finished. After the class, students were mostly tired and therefore did not normally cooperate with the researcher. As this study was merely a quantitative research whose sample was less than 100 , it is suggested for those who want to replicate this study it is preferred to use a mixed method paradigm to find answers to research questions, they can also use a follow up interview alongside the questionnaire.

\section{References}

Bernaus, M., \& Gardner, R. C. (2008).Teacher motivation strategies, students' perceptions, student motivation, and English achievement. The Modern Language Journal, 92, 387-401.

Boss, M. W., \& Taylor, M. C. (1989).The relationship between locus of control and academic level and sex of secondary school students. Contemporary Educational Psychology, 14, 315-322.

Brophy, J. (2010). Motivating students to learn. New York, NY: Routledge.

Burke, P. J. (1989). Gender identity, sex, and school performance. Social Psychology Quarterly, 52, 159-169.

Burke, P. J. (1989). Gender identity, sex, and school performance. Social Psychology Quarterly, 52, 159-169.

Cray, E. \& Currie, P. (1996). Linking adult learners with the education of L2 teachers. TESOL Quarterly, 30 (1), 113-130.

Dornyei, Z. (1994). Motivation and motivating in the foreign language classroom. The Modern Language Journal, 78, 273-284.

Dornyei, Z. (1998). Motivation in second and foreign language learning. Language Teaching, 31, 117-135.

Dornyei, Z. (2007). The psychology of the language learner. US: Lawrence Erlbaum Associates.

Gentry, M., \& Gable, R. K. (2001). My Class Activities: A survey instrument to assess students' perceptions of interest, challenge, choice, and enjoyment in their classrooms. Mansfield Centre, CT: Creative Learning Press.

Gentry, M., Maxfield, L. R., \& Gable, R. K. (1998). Construct validity evidence for enrichment clusters and regular classrooms: Are they different as students see them? Educational and Psychological Measurement, 58, 258-274.

Gorham, J., \& Christopher, D. M. (1992). Students' perception of teacher behaviors as motivating and demotivating factors in college classes. Communication Quarterly, 40, 239-252.

Nakata, Y. (2006). Motivation and experience in foreign language learning. Oxford, UK: Peter Lang AG.

Nikolov, M. (1999). "Why do you learn English?" "Because the teacher is short." A study of Hungarian children's foreign language learning motivation. Language Teaching Research, 3(1), 33-56.

Orenstein, P. (1994). Schoolgirls: Young women, self-esteem, and the confidence gap. New York: Doubleday.

Sugita, M., and Takeuchi, O. (2010). What can teachers do to motivate their students? A classroom research on motivational strategy use in the Japanese EFL context. Innovation in Language Learning and Teaching, 4(1), 21-35. 